Research Article

\title{
Coupling of Contact Nucleation Kinetics with Breakage Model for Crystallization of Sodium Chloride Crystal in Fluidized Bed Crystallizer
}

\author{
Dan Zheng $(\mathbb{D}$, Wei Zou, Jie Yan, Chuanfeng Peng, Yuhang Fu, Bo Li, Li Zeng, \\ Tinghong Huang, and Fengzhen Zhang \\ Department of Chemical Engineering, Sichuan University of Science \& Engineering, Zigong, Sichuan 643000, China \\ Correspondence should be addressed to Dan Zheng; zhengdan0830@163.com
}

Received 24 June 2019; Accepted 31 August 2019; Published 18 September 2019

Academic Editor: Sedat Yurdakal

Copyright $(2019$ Dan Zheng et al. This is an open access article distributed under the Creative Commons Attribution License, which permits unrestricted use, distribution, and reproduction in any medium, provided the original work is properly cited.

There are many nucleation theory-based different mechanisms. These theories mainly focused on production parameters in the crystallization and less on physical properties of crystals. In this research, a new model of contact nucleation theory coupled with the breakage mechanism of crystals is applied to describe the collision process in sodium chloride crystallization. This coupling nucleation model is presented here which relates the number of contact-collision site in nucleation owing to collision rate and the interfacial energy. $F_{2}$ in the expression of the classic contact nucleation rate is redefined as a power function with the physical properties of crystals and breakage propensity. The experiment results indicate that crystal breakage propensity has a significant influence on the nucleation rate. Finally, analysis of the contact nucleation kinetic model and comparison with experiments reveal that the new nucleation model results are in better agreement with experiments. This new nucleation model is confirmed to represent the time-dependent collision behavior. The parameters of model are strongly related to the physical properties of crystal and fluidization conditions.

\section{Introduction}

The process of fluidized crystallization has the characteristics of variable crystal movements and complex fluidization behavior. Hence, it has received more attention due to its high mass transferring efficiency and well multiphase mixing compared to stirring-type crystallizer. Nucleation is a crucial step in crystallization. It can be categorized as heterogeneous, homogeneous, and secondary. Heterogeneous or homogeneous nucleation is self-generated. Secondary nucleation appears mere because of the presence of parent seed crystals. It mainly includes fluid shear nucleation and contact nucleation [1]. The fluid shear nucleation demonstrates that fluid stress forces the effect of production of secondary nuclei, presumably by shearing fragments from the surface of seed crystal [2]. The contact nucleation was termed also as collision breeding or collision nucleation. The collisions or contacts between crystals have visible effects in the parent crystal. The fragmentation produced by collision leaves impressions on the crystal surface. The contact nucleation is the most important mechanism of nucleation. A large number of fragments produced by mechanical contact become the source of nuclei and influence the crystal size distribution [3]. This type of nucleation should be particularly active in the high-supersaturation regions of an industrial suspension crystallizer.

There are many factors that influence contact nucleation but one of the most important ones is the breakage. In an FBC, the crystals are in dynamic motion and subjected to mechanical stresses caused by collisions, thereby resulting in crystal breakage. In this procedure, the crystals can have deformation and break. Breakage is mainly a consequence of collisions with other crystals. The appearance of this phenomenon depends on the intensity of collision and the physical properties of the crystal. Owing to the breakage between crystals due to too strong collision force, a great quantity of fine fragments is produced in solution and triggers secondary nucleation. Breakage appears widely 
during the crystallization, which has a significant influence on the final quality of the product. Not only that, but the fluidization conditions may also alter significantly. Furthermore, the fragments produced by breakage can generally cause serious problems such as equipment blocking, potential damage for downstream equipment, and environmental pollution [4].

Due to the lack of understanding of the mechanism of crystal breakage, the prediction of nucleation rate often fails to give accurate values. Therefore, the influence of crystallization kinetics and breakage mechanism on nucleation needs to be thoroughly understood so as to evaluate the operation performance of fluidized bed crystallizer. As per the valuable literature, there is no systematic report available on nucleation kinetics involving breakage theory of crystals. In this research, the objective of the present work is to develop a nucleation kinetic model considering the fragmentation effects produced by the collision process in nucleation of crystals. This is followed by experimental measurement of the breakage of sodium chloride crystals in a laboratory-scale fluidized bed crystallizer using different circulation flow rates and residence time.

\section{The Classic Theory of Crystal Contact Nucleation}

The nucleation rate of crystals is determined by the secondary nucleation property of the crystalline material and the fluid flow characteristics of the solution in the crystallizer. The contact nucleation process for sodium chloride crystals is shown in Figure 1. The deformation rate of nuclei originating from collisions is determined by the surface morphology of the crystals, collision energy, and collision frequency. The impact of energy and frequency is investigated by the characteristics of the crystallizer and crystal suspension. Botsaries discussed that the growth properties of crystal nucleus produced by the collision process seem to be distinct considerably from those of larger crystals, and $B_{s}$ is calculated on the basis of theory [5]:

$$
B_{\mathrm{s}}=E_{\mathrm{T}} F_{1} F_{2} \text {, }
$$

where $B_{\mathrm{s}}$ is the nuclei formation rate, originating from secondary nucleation in crystallization. The nucleation expression can be divided into three parts: the energy transfer rate to crystals by collision $\left(E_{\mathrm{T}}\right)$, the number of fragments produced per unit of transferred energy $\left(F_{1}\right)$, and the fraction of fragments to form nuclei $\left(F_{2}\right)$.

Due to the lack of understanding of the nucleation mechanism, the above two functions cannot be represented by mathematical equations. It is recommended to use an exponential function that includes supersaturation or fluid shear forces. Based on the Botsaries model, the nucleation rate is defined by the following equation [6]:

$$
B_{\mathrm{s}}=K_{\mathrm{B}} f(\mathrm{Geom}) \Delta c^{i} M_{\mathrm{T}}^{k} N^{j},
$$

where $K_{\mathrm{B}}$ is the secondary nucleation rate constant. The exponent in the above equation indicates the nucleation order. These are empirically fitted coefficients and represent

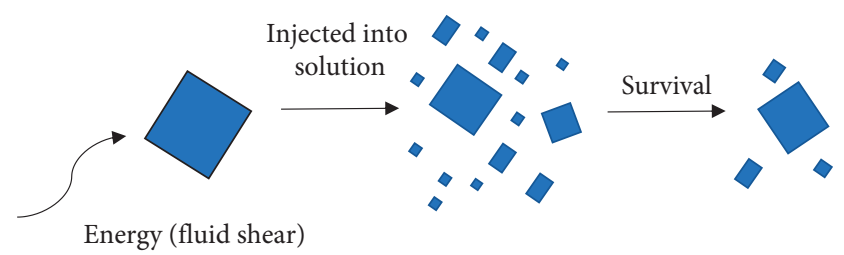

Figure 1: The contact nucleation in crystallizers.

the degrees of freedom of the model in this paper. The constants $\Delta c$ and $M_{\mathrm{T}}$ represent the supersaturation and suspension density, respectively. The secondary nucleation rate constant is expressed as

$$
K_{\mathrm{B}}=k_{0} \exp (-E / R \mathrm{~T})
$$

where the symbol $k_{0}$ is the preexponential factor [7], $E$ denotes the corresponding activation energy, $R$ is the universal gas constant, and $f(\mathrm{Geom})$ is a function of the crystallizer geometric size. Since the crystallizer has a similar geometry and size, the feature size parameter $\lambda$ is introduced to simplify the following expression [8]:

$$
B_{\mathrm{s}} \propto K_{\mathrm{B}} \lambda^{d} \Delta c^{i} M_{\mathrm{T}}^{k} N^{j} .
$$

The value of nucleation rate can be evaluated as a function relation of solution supersaturation $(\Delta c)$, suspension density $\left(M_{\mathrm{T}}\right)$, and fluid shear force $(N)$ from the correlation reported by Mucci:

$$
B_{\mathrm{s}}=K_{\mathrm{B}} \Delta c^{i} M_{\mathrm{T}}^{k} N^{j} .
$$

The assembly nucleation rate is estimated as the sum of primary nucleation rate and secondary nucleation rate (this paper shows that the fluid shear force is expressed by Reynolds):

$$
B_{0}=B_{\mathrm{s}}+B_{\mathrm{p}}=K_{\mathrm{B}} \Delta c^{i} M_{\mathrm{T}}^{k} e^{j} .
$$

\section{The Crystal Breakage Model}

3.1. The Collision Parameter. The collision force between crystals can not to be neglected in the process of contact nucleation. It is important to make a theoretical analysis for this force to understand how they can affect breakage. It can be calculated by Newton's law:

$$
F=m \frac{d V}{d t}=\rho l^{3} \frac{d V}{d t},
$$

where $l$ denotes the characteristic length of crystal, $V$ is the collision rate, and $\rho$ is the crystal density. It is hard to calculate the differential part of above equation (crystal acceleration: $d V / d t)$. For this reason, the peak collision time $t_{\mathrm{p}}$ is introduced to simplify the expression based on a twopoint difference method:

$$
\frac{d V}{d t} \approx \frac{V}{t_{\mathrm{p}}}
$$

$t_{\mathrm{p}}$ stands for the time spent from the initial collision until the force attains its maximal value. By substituting equation (8) in (7), the following expression is obtained: 


$$
F \approx \rho l^{3} \frac{V}{t_{\mathrm{p}}} .
$$

The peak collision time $t_{\mathrm{p}}$ plays a significant role in the collision process. $t_{\mathrm{p}}$ can be deemed to include the elastic and plastic period. In the elastic times, the collision force of the contact zone rises into the certain value at which plastic flow arises. In the plastic times, plastic flow takes place until the relative rate between the two crystals goes to zero under the combined effect of plastic and elastic forces.

Because the plastic flow happens at the initial period during the collision process of crystals, the plastic time is the leading factor. The peak collision time driven by plastic collision has been expressed as follows [9]:

$$
t_{\mathrm{p}}=\frac{1}{2} \sqrt{\frac{m \pi}{H d}}
$$

where $H$ is the hardness of crystal and $d$ denotes the crystal characteristic size. The peak collision time can be approximately evaluated as follows:

$$
t_{\mathrm{p}} \propto l \sqrt{\frac{\rho}{H}}
$$

To summarize, it is found that the peak collision time is directly proportional to the crystal size and inversely proportional to the crystal hardness. Meanwhile, the collision rate does not seem to have no effect on the peak collision time.

3.2. The Impress Size of Crystal. The impress size of crystal produced by plastic flow is the fundamental analysis of the indentation fracture. It is the direct feedback of crystal to collide. The impress size of collision $a$ can take the form approximately in line with the hardness and collision force [10]:

$$
a \propto \sqrt{\frac{F}{H}} .
$$

Equation (12) provides a simple functional relationship between the size of impression and collision force. Substituting equation (12) into equation (9), we can obtain the consummate form of impress size expressed by the peak collision time:

$$
a \propto \sqrt{\frac{\rho l^{3} V}{H t_{\mathrm{p}}}} .
$$

It is found that the size of impression can predicted by $t_{\mathrm{p}}$. We can continue to simply the above function by substituting equation (13) into equation (11). Finally, the impress size of crystal is estimated based on the crystal density, crystal characteristic size, and collision rate using the following equation:

$$
a \propto l V^{1 / 2}\left(\frac{\rho}{H}\right)^{1 / 4} .
$$

Analyzing equation (14), we conclude that impression size of crystal depends on material properties and geometry.
It increases as the crystal density, crystal characteristic size, and collision rate increased, and the opposite tendency is presented with hardness.

3.3. The Parameter of Crystal Breakage Model. In fluidized bed, crystal breakage produces a great quantity of fine debris. In general, the breakage mechanisms can be explained by indentation fracture of crystal surface. For indentation fracture, the crack extension mainly relies on the strain energy release rate. However, an understanding of crack extension has not been explored so far due to the sophisticated mechanisms of crack deformation. In this research, it is suggested that the formation of crack takes place after a certain amount of stress is introduced. The form of crack extension can be written in the following form:

$$
\frac{c}{a} \propto\left(\frac{K_{c}}{H \sqrt{a}}\right)^{-1}
$$

where $K_{c}$ is the critical stress intensity factor and $c$ is the length of crack. The crystal materials have been investigated that the collision loss to a corner of a single crystal is in the form of plastic deformation, followed by the formation of tiny debris from the surfaces with the collision point nearby. The process of collision is displayed in Figure 2. The collision leads to an impression zone on a plane parallel to the crystal surface. The fractional loss per collision is estimated by the following equation:

$$
\xi \propto \frac{c^{2} h}{l^{3}},
$$

where $h$ is the depth of crack. To simply this research, the crack depth is approximately equal to the length of crack $(h \approx a)$. Substituting equations (15) and (16) into equation (10), the fractional loss per collision can be given by the following equation:

$$
\eta=\frac{\rho V^{2} l H}{K_{c}^{2}},
$$

where $\eta$ is defined as a dimensionless breakage propensity parameter that involves the relevant physical properties of the crystal. This crystal breakage model is deduced on the basis of indentation fracture theory. The fractional loss per collision is considered to be determined by the breakage propensity parameter.

3.4. The Nucleation Kinetics Coupled with the Crystal Breakage Model. In this work, the contact nucleation kinetics coupled with the crystal breakage model is applied to describe the crystallization process of sodium chloride crystal. We proposed a new approach for evaluating the collision behavior of crystals occurring in nucleation. This method is based on the energy balance approach. The kinetic energy of the crystals before collision is defined as

$$
E_{k}=N \frac{1}{2} m V^{2},
$$




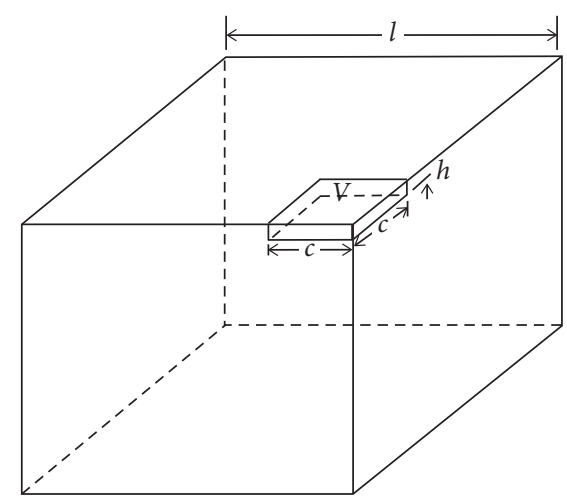

Figure 2: Schematic diagram of the volume of debris removed from the crystal surface.

where $N$ is the number of crystals in the contact nucleation and $m$ is the mass of crystal. Assuming the collision area of each contact site is approximately the same, then

$$
N_{\mathrm{B}} \Gamma A=N \frac{1}{2} m V^{2}
$$

where $N_{\mathrm{B}}$ is the number of contact-collision site, $\Gamma$ is the interfacial energy of contact site, and $A$ is the area of each contact-collision site. The mass of crystal can be expressed by crystal volume and density:

$$
m=\frac{1}{3} \pi d^{2} \rho
$$

Substituting $m$ of equation (20) into equation (19), $N$ can be written as follows:

$$
N=\frac{N_{\mathrm{B}} 6 \Gamma A}{\pi V^{2} \rho d^{2}} .
$$

The contact area can be expressed as a function of the crystal physics properties and the interface energy from which the contact area $A$ can be given as follows [11]:

$$
A=\left(\frac{3}{4}\right)^{4 / 3} \pi^{5 / 3}\left(1-v^{2}\right)^{2 / 3}\left(\frac{d^{2}}{E} \Gamma\right)^{2 / 3},
$$

where $v$ is Poisson's ratio. Substituting $A$ in equation (22) into equation (21), the ratio of number of contact-collision sites to crystals can be expressed as

$$
\frac{N}{N_{\mathrm{B}}}=\frac{\rho d^{2 / 3} V^{2} E^{2 / 3}}{6(3 / 4)^{4 / 3} \pi^{2 / 3}\left(1-v^{2}\right)^{2 / 3} \Gamma^{5 / 3}} .
$$

Meanwhile, the relationship between the interfacial energy, elastic modulus, the critical stress intensity factor, and Poisson's ratio can be written from the following functional form:

$$
E \Gamma=K_{c}^{2}\left(1-v^{2}\right)
$$

Substituting $\left(1-v^{2}\right)$ of equation (24) into equation (23), Equation (23) can be rewritten as

$$
\frac{N}{N_{B}} \propto \frac{K_{c}^{4 / 3} \rho d^{2 / 3} V^{2}}{\Gamma^{5 / 3} \pi^{2 / 3}} .
$$

After substitution of equation (17) into equation (25), the form of the relationship between number of contact-collision sites and crystals can be expressed as

$$
\frac{N}{N_{B}} \propto \eta \frac{K_{c}^{10 / 3}}{\Gamma^{5 / 3} \pi^{2 / 3} d^{1 / 3} H}
$$

As it will be shown in equation (1), $F_{2}$ in the expression of contact nucleation rate generally depends on the properties of the contact nuclei produced by the collision. These properties mainly involve characteristics of growth, collision process, and deformation of nuclei. Assuming the number of contact-collision sites has certain function in relation with the fraction of nuclei, and it then follows that

$$
B_{\mathrm{s}} \propto K_{\mathrm{B}} \Delta c^{m}\left(\eta \frac{K_{c}^{10 / 3}}{\Gamma^{5 / 3} \pi^{2 / 3} d^{1 / 3} H}\right)^{n} .
$$

This new nucleation kinetic model involves the process operating conditions of the crystallization system and the changes of crystal physical properties caused by the collision process. The contact nucleation kinetics can be developed on the basis of the concentration driving force called supersaturation, breakage propensity, and relevant physical properties of crystal.

\section{Experiments}

4.1. Experimental Setup. The experimental drawing of fluidized bed crystallizer is shown in Figure 3. Recirculation pumps are used to introduce the supersaturated solution near the bottom of the FBC. The temperature inside the crystallizer is controlled with a temperature probe. The experiment is conducted at room conditions. The supersaturated solution is pumped upward to guarantee fluidization of the crystal seeds in order to prevent cementing [12]. A buffer tank between crystallizer and heat exchanger guarantees that the solution has no seed crystals. After leaving the buffer tank, the fluid is introduced to the heat exchanger, where it is saturated again by reducing the temperature. By using the $\mathrm{pH}$ probe, it is also critical to prevent cocrystallization of other components in solution. The crystallizer expansion is controlled by adjusting the internal circulation rate. The large crystals accumulating at the crystallizer bottom are withdrawn and are oven-dried at $130^{\circ} \mathrm{C}$ for about $2.5 \mathrm{~h}$. Then, sodium chloride crystals are harvested. The properties of crystal are concluded in Table 1.

4.2. Experimental Method for Nucleation Rate. Nucleation refers to the composition of tiny crystals from fine seed. In an FBC, the breakage of crystals is deemed to occur merely due to fluid stress and not due to collisions between small granules [13]. The generation of tiny nucleus debris by fluid stress is also contained in the nucleation rate. The crystal mass on different aperture sieves can be analyzed after separating by sieving, and the number of crystal particles of different sizes can be calculated. The number of crystals on each sieve is also calculated using equation (28), and the calculated results are 


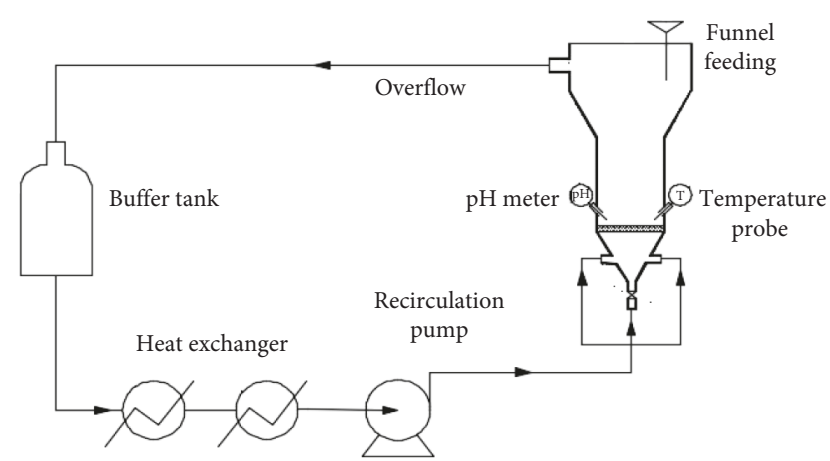

Figure 3: The experimental flow chart of the fluidized crystallization system.

TABle 1: Characteristics of sodium chloride seed crystals.

\begin{tabular}{lc}
\hline Seed characteristics & Values \\
\hline Crystallite size $(\mathrm{mm})$ & $0.0265-0.358$ \\
Crystal structure & Hexahedron \\
Hardness $\left(10^{9} \mathrm{Nm}^{-2}\right)$ & 0.19 \\
Poisson's ratio & 0.209 \\
Interfacial energy $\left(\mathrm{Jm}^{-2}\right)$ & 0.34 \\
Critical stress intensity factor $\left(10^{5} \mathrm{Nm}^{-3 / 2}\right)$ & 1.8 \\
Density $\left(\mathrm{g} / \mathrm{cm}^{3}\right)$ & 2.238 \\
Volume $\left(\mathrm{cm}^{3}\right)$ & 0.894 \\
Mass $(\mathrm{g})$ & 1 \\
\hline
\end{tabular}

summed to obtain the total number of crystals $\left(N_{\text {all }}\right)$. Crystal nucleation rate $\left(B_{0}\right)$ can be expressed by equation (29):

$$
\begin{aligned}
& N=\frac{m_{\mathrm{s}}}{\left(4 \pi r^{3} \rho_{\mathrm{c}} / 3\right)}, \\
& B_{0}=\frac{\left(N_{\mathrm{all}}-N\right)}{\tau V},
\end{aligned}
$$

where $\rho_{\mathrm{c}}$ is the crystals density, $m_{\mathrm{s}}$ is the crystal mass on each sieve, and $\tau$ is the experiment time. The Sauter mean diameter $\left(d_{32}\right)$ is usually used as the mean particle size. Sauter average size in an FBC can be expressed as follows:

$$
d_{32}=\frac{\sum_{i} d_{i}^{3} n_{i}}{\sum_{i} d_{i}^{2} n_{i}}
$$

where $n_{i}$ is the number of the crystals of size $d_{i}$ on $i$ th aperture sieve. The coefficient of variation (C.V.) is a statistical measure of the dispersion of data points in a data series around the crystal mean particle size. The coefficient of variation represents the ratio of the standard deviation to the mean particle size, it is a useful statistic for comparing the degree of variation from one data series to another, and it can be given by the following equation:

$$
C . V .=\frac{\sqrt{\left(\left(d_{1}-d_{32}\right)^{2}+\left(d_{2}-d_{32}\right)^{2}+\cdots+\left(d_{n}-d_{32}\right)^{2}\right) / n}}{d_{32}} .
$$

\section{Results and Discussion}

\subsection{The Influence of Process Conditions on Crystal Breakage}

5.1.1. Metastable Zone Width and Induction Period. The saturated solution of sodium chloride is prepared on the basis of solubility data. In this research, the metastable zone width of sodium chloride is measured by the conventional polythermal method [14]. The breaker with saturated solution is placed on the constant temperature bath. The solution is heated to $10^{\circ} \mathrm{C}$ above the saturated temperature for homogenization. The cooling is carried out until observation of the first crystal after attaining the stabilization. The temperature at which the crystal appears is defined as the nucleation temperature. This experiment is carried out for the solution saturated at $30,40,50,60$, and $70^{\circ} \mathrm{C}$. Repeated trials are performed to ascertain the correctness of the observed results. The difference between the saturated temperature and the nucleation temperature considered to be the metastable zone width of the crystallization is shown in Figure 4. It can be concluded from Figure 4 that the solubility increases with an increase in temperature and nucleation temperature increases with the increase in concentration. And the metastable zone width is broader at lower temperature and narrow at higher temperature of the solution. The degree of nucleation rate not only depends on the intermolecular distances of the solute particles in the solution but also on its concentration. The stability of solution with wide metastable zone width is useful for the crystallization.

The time spent between the achievement of supersaturation and the appearance of first nucleus in solution is known as the induction period, as shown in Figure 5. The research of the induction period under supersaturation gives a guidance to control the nucleation rate for obtaining high quality crystals. In the present work, the direct vision observation method is applied to measure the induction period. Figure 6 displays the relationship between induction period with the solution supersaturation. It shows that the induction period decreases with supersaturation which suggests that the nucleation rate increases.

5.1.2. The Circulation Flow Rate. In general, there are two breakage modes for crystal in FBC: fragmentation and surface abrasion [15]. To determine the breakage modes in this study, the experiments are performed with four different circulation flow rates. Figure 7 shows the crystal size distribution (CSD) retained after $1200 \mathrm{~s}, 2100 \mathrm{~s}, 3000 \mathrm{~s}$, and $3600 \mathrm{~s}$ of residence time for the different circulation flow rates, which indicates clearly that the crystal fragmentation mechanism predominated. Figure 7 (a) shows that, for a given residence time, the mass fraction of crystals in the size range $0.245-0.269 \mathrm{~mm}$ is larger for a circulation flow rate of $0.3454 \mathrm{~m} / \mathrm{s}$ compared with other flow rates. It can be concluded that a boundary layer is formed on the surface of crystal, and increasing the flow rate will result in a thinner boundary layer, which is more conducive to crystal growth. 


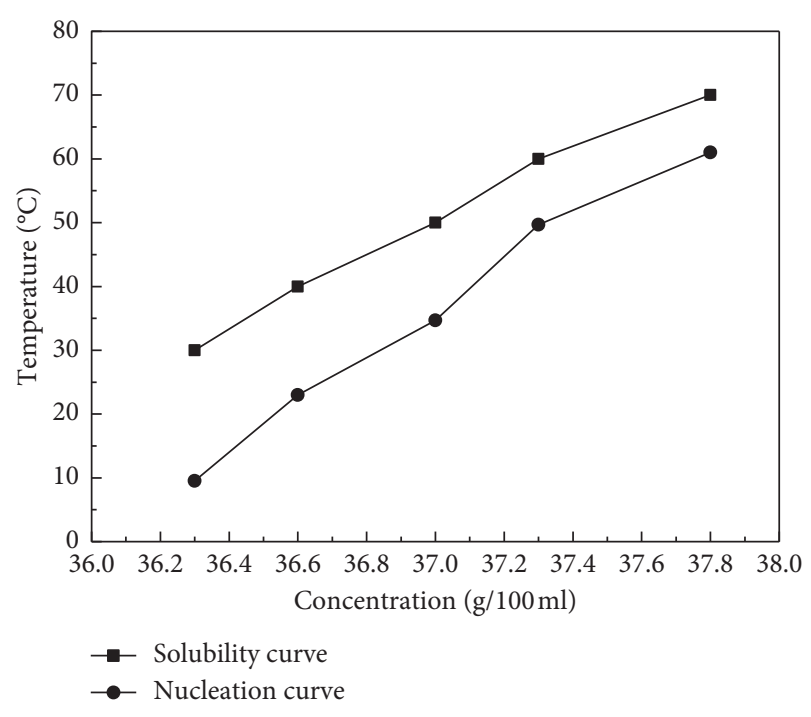

FIgURE 4: Metastable zone width of sodium chloride.

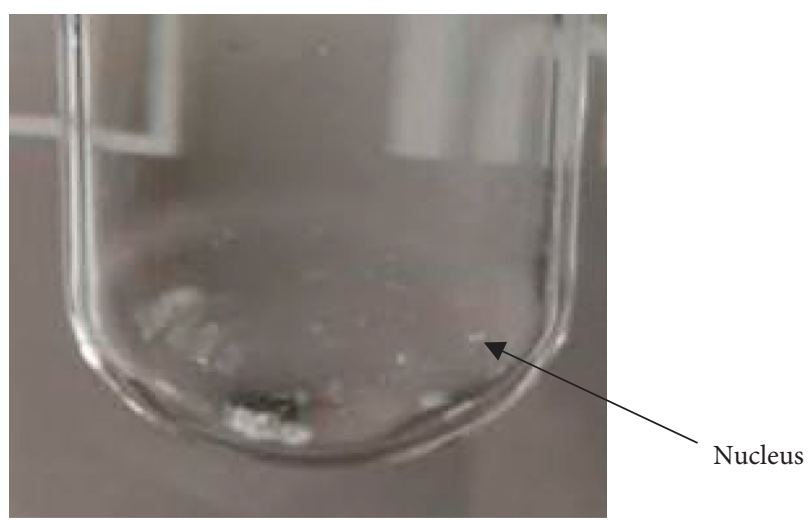

FIGURE 5: The photograph of sodium chloride nucleus.

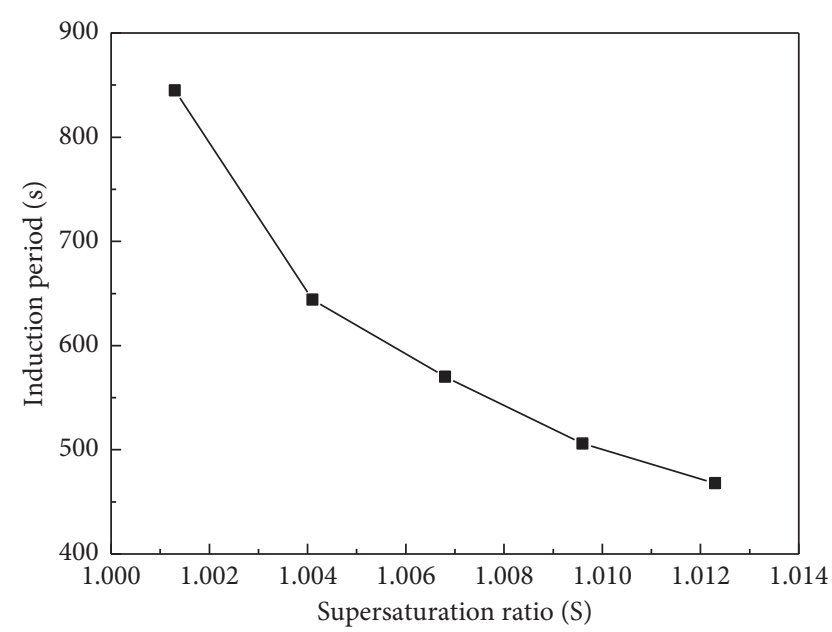

FIGURE 6: Induction period versus supersaturation ratio of sodium chloride.

When the flow rate is too high, the high circulation flow rates trigger more crystal-crystal interactions. These interactions lead to a large amount of crystal debris to be generated, resulting in an increase in the mass fraction of small crystals. In Figures $7(\mathrm{~b})-7(\mathrm{~d})$, the mass fraction of crystals with larger diameters is less at a circulation flow rate of $1.3816 \mathrm{~m} / \mathrm{s}$ than those of the other flow rates. These results indicate that the probability of breakage of crystals with large size is increased at higher circulation flow rates and longer residence times.

To better evaluate the effects of the process condition on the breakage of the crystal, we discussed the threshold size distribution of crystal. Figure 8 displays the relationship between mass fraction of crystals less than $0.245 \mathrm{~mm}$ and residence time. It can be seen that the production of crystal less than $0.245 \mathrm{~mm}$ promoted increasing residence time. Meanwhile, the generation of fine debris is greater at a circulation flow rate owing to greater collision of crystals. We found a sharp decrease in crystal mass fraction at a residence time of $3600 \mathrm{~s}$. This can be ascribed to the long period of operation of the fluidized bed, resulting in some small crystals being washed away. This situation is also reflected in the variation trend of mass fraction of large crystal (Figure 9). So the proper operating time is also a significant factor to be considered in fluidized crystallization.

A scanning electron microscope (SEM) images represent the CSD, and shapes are displayed to clearly illustrate the breakage mode. As shown in Figure 10, the seed crystals are roughly spherical and have a smooth shape. After breakage, the number of small debris increases significantly. It can be concluded that there are in good agreement with the CSD in Figure 7.

\subsubsection{The Sauter Mean Size and the Coefficient of Variation.} The Sauter mean size is investigated to better explain the continuous breakage of crystal in an FBC. Table 2 shows the number of crystals at each sieve size. The Sauter mean size can be obtained by applying equation (30). As can be seen in Figure 11, due to the breakage of crystal, the Sauter mean size has a certain degree of reduction at all circulation flow rates when residence time is longer than $2100 \mathrm{~s}$. It can be attributed to that the higher residence time promoted crystal-crystal collisions and abrasion of the crystals resulted in reduced crystal diameters. Figure 12 shows the time-dependent change of the coefficient of variation of crystal. The larger the coefficient of variation (C.V.) of the crystal, the wider the crystal size distribution; the smaller the C.V., the narrower the crystal size distribution, and the more uniform the crystal size. In $2100 \mathrm{~s}$, the coefficient of variation at all flow rates reached the lowest point. It shows that the size distribution of crystals is the most uniform at this time. Meanwhile, the C.V. increased to 0.287 at a circulation flow rate of $1.3816 \mathrm{~m} / \mathrm{s}$. These results indicate that smaller particles with a broader size range are generated at a higher circulation flow rate. Meanwhile, the best residence time $(2100 \mathrm{~s})$ is given according to the experimental results and analysis. The following studies on nucleation kinetics are based on the above results. 


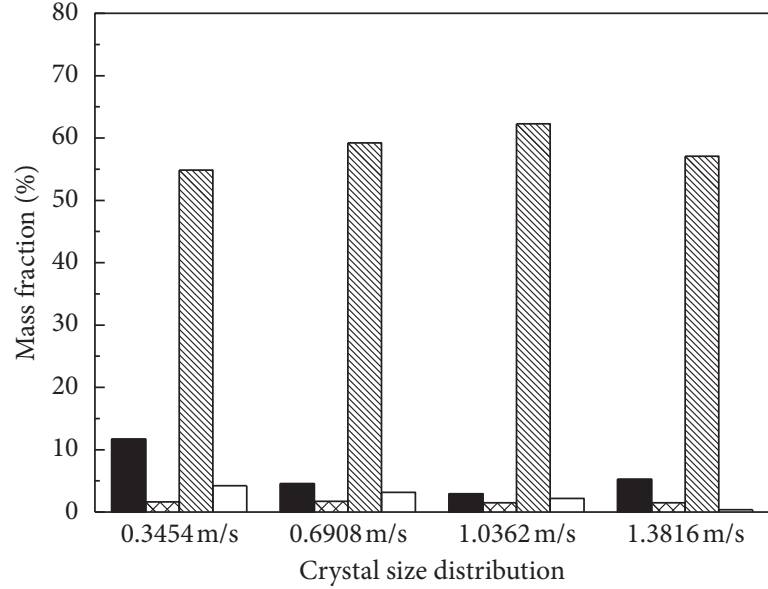

$0.245 \mathrm{~mm}-0.269 \mathrm{~mm} 0.297 \mathrm{~mm}-0.325 \mathrm{~mm}$ QX $0.269 \mathrm{~mm}-0.297 \mathrm{~mm} \square 0.325 \mathrm{~mm}-0.350 \mathrm{~mm}$

(a)

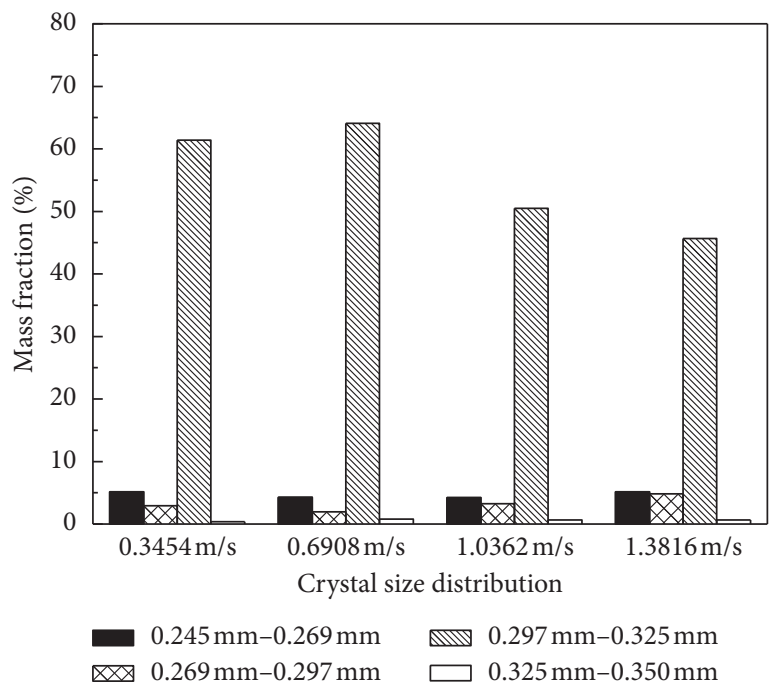

(c)

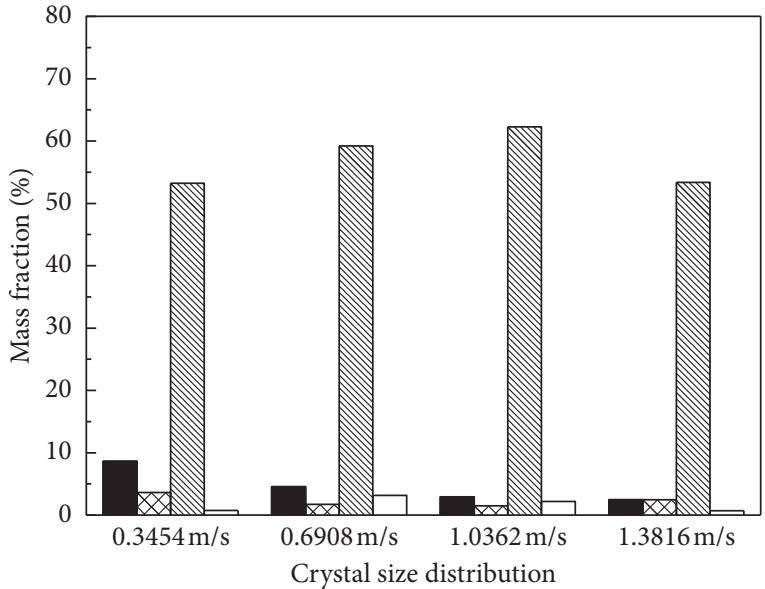

$0.245 \mathrm{~mm}-0.269 \mathrm{~mm} 0.297 \mathrm{~mm}-0.325 \mathrm{~mm}$ $0.269 \mathrm{~mm}-0.297 \mathrm{~mm} \square 0.325 \mathrm{~mm}-0.350 \mathrm{~mm}$

(b)

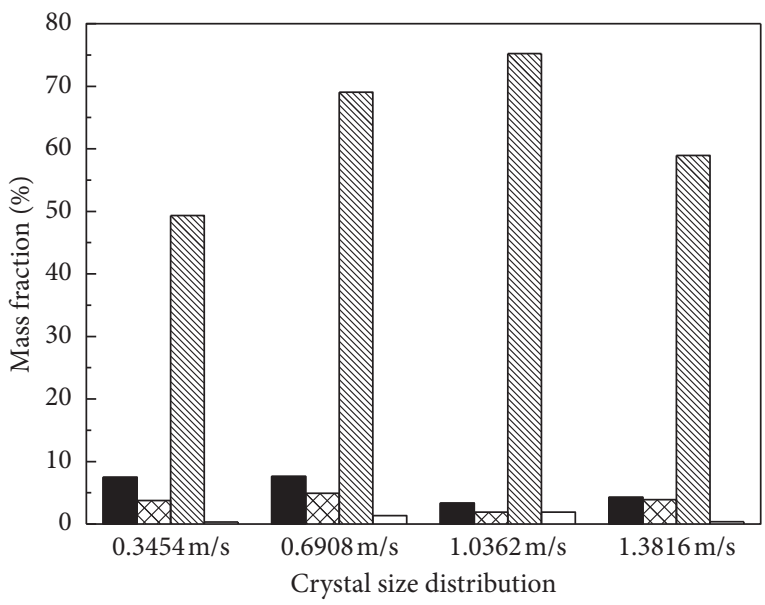

$0.245 \mathrm{~mm}-0.269 \mathrm{~mm} \quad 0.297 \mathrm{~mm}-0.325 \mathrm{~mm}$ $\square \times 0.269 \mathrm{~mm}-0.297 \mathrm{~mm} \square 0.325 \mathrm{~mm}-0.350 \mathrm{~mm}$

(d)

FIgURE 7: The influence of circulation flow rates on CSD for residence times of (a) $1200 \mathrm{~s}$, (b) $2100 \mathrm{~s}$, (c) $3000 \mathrm{~s}$, and (d) $3600 \mathrm{~s}$.

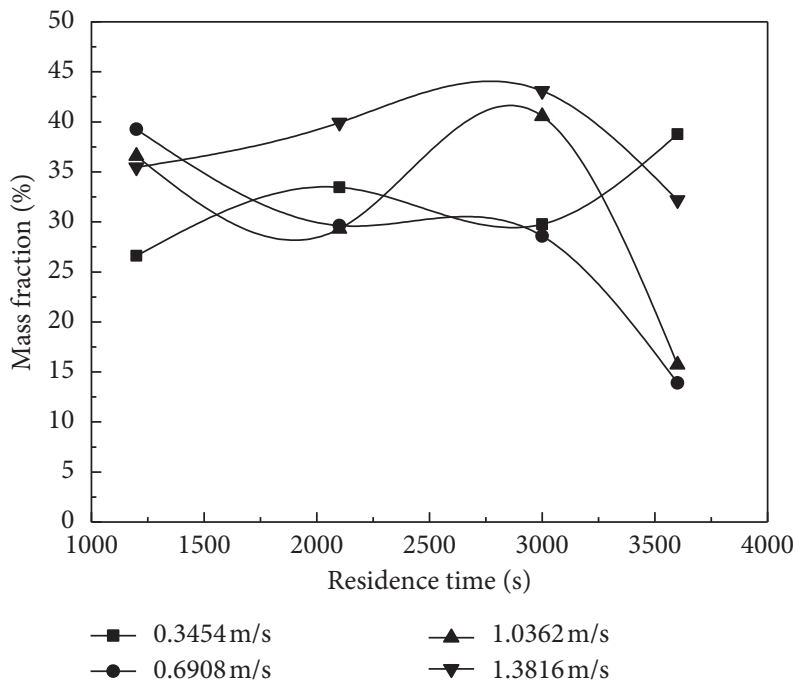

FIGURE 8: The influence of circulation flow rates on mass fraction of crystal of size less than $0.245 \mathrm{~mm}$ for different residence times.

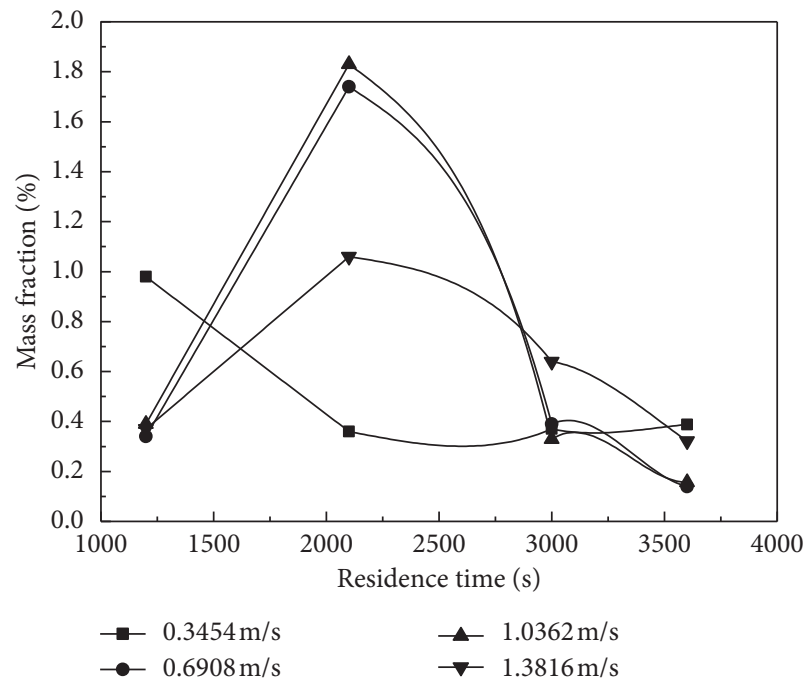

FIGURE 9: The influence of circulation flow rates on mass fraction of crystal of size larger than $0.350 \mathrm{~mm}$ for different residence times. 


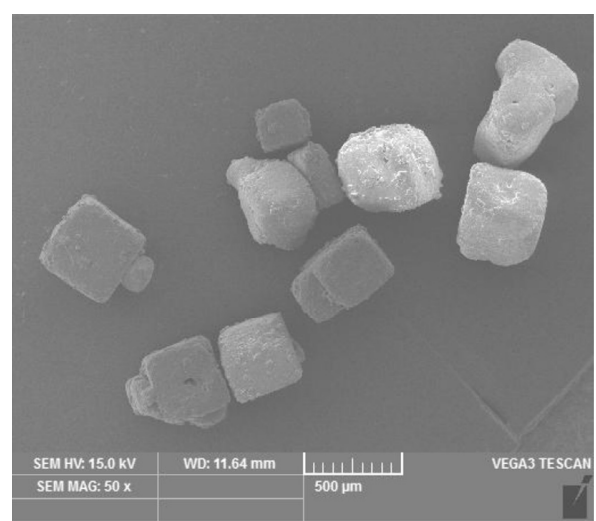

(a)

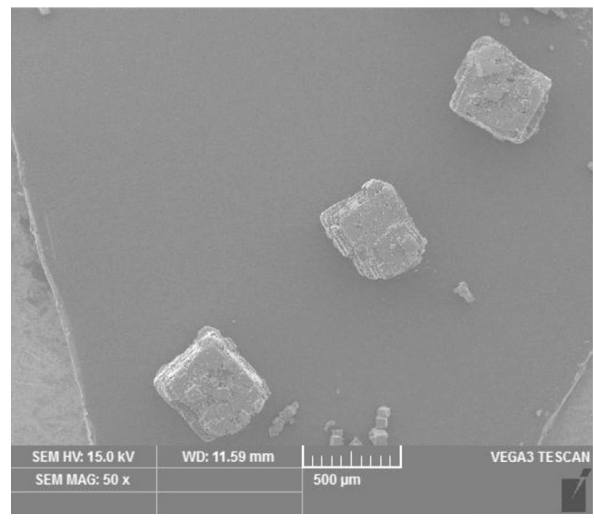

(c)

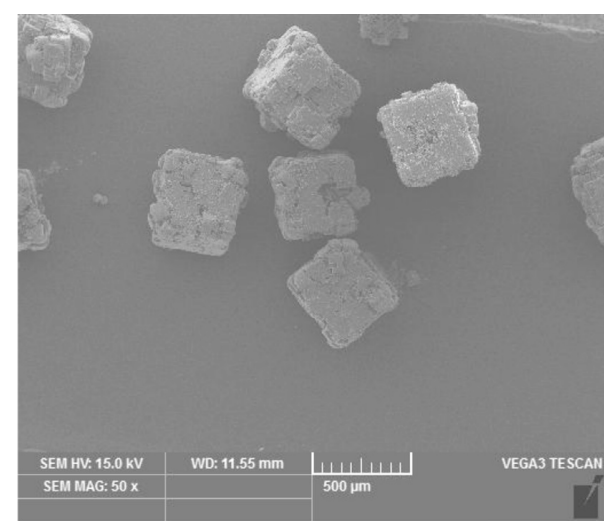

(b)

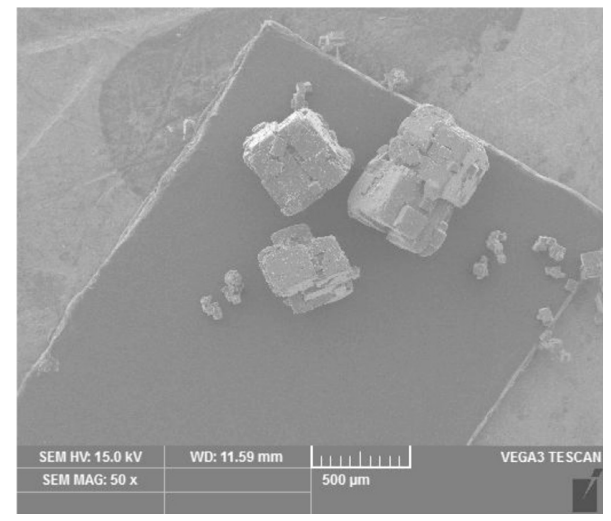

(d)

FIGURE 10: SEM images of crystal before and after breakage: (a) the seed crystals; (b) $2100 \mathrm{~s}$; (c) $3000 \mathrm{~s}$; (d) $3600 \mathrm{~s}$.

TABLE 2: Crystal breakage of different operation conditions.

\begin{tabular}{|c|c|c|c|c|c|c|c|}
\hline \multirow{2}{*}{ Residence time } & \multirow{2}{*}{ Circulation flow rate } & \multicolumn{6}{|c|}{ Number of crystals on each size range (\%) } \\
\hline & & $<0.245 \mathrm{~mm}$ & $0.245-0.269 \mathrm{~mm}$ & $0.269-0.297 \mathrm{~mm}$ & $0.297-0.325 \mathrm{~mm}$ & $0.325-0.350 \mathrm{~mm}$ & $>0.350 \mathrm{~mm}$ \\
\hline \multirow{4}{*}{$1200 \mathrm{~s}$} & $0.3454 \mathrm{~m} / \mathrm{s}$ & 9769 & 5871 & 1024 & 10525 & 235 & 136 \\
\hline & $0.6908 \mathrm{~m} / \mathrm{s}$ & 1370 & 5394 & 735 & 10662 & 108 & 55 \\
\hline & $1.0362 \mathrm{~m} / \mathrm{s}$ & 11198 & 4059 & 904 & 11198 & 86 & 77 \\
\hline & $1.3862 \mathrm{~m} / \mathrm{s}$ & 11317 & 5182 & 786 & 9901 & 94 & 52 \\
\hline \multirow{4}{*}{$2100 s$} & $0.3454 \mathrm{~m} / \mathrm{s}$ & 9767 & 6883 & 1275 & 11613 & 98 & 60 \\
\hline & $0.6908 \mathrm{~m} / \mathrm{s}$ & 10126 & 4811 & 1445 & 11560 & 461 & 275 \\
\hline & $1.0362 \mathrm{~m} / \mathrm{s}$ & 9530 & 2961 & 1584 & 11670 & 279 & 247 \\
\hline & $1.3862 \mathrm{~m} / \mathrm{s}$ & 11317 & 2591 & 1086 & 12276 & 137 & 207 \\
\hline \multirow{4}{*}{$3000 \mathrm{~s}$} & $0.3454 \mathrm{~m} / \mathrm{s}$ & 9649 & 5404 & 768 & 10298 & 65 & 35 \\
\hline & $0.6908 \mathrm{~m} / \mathrm{s}$ & 8816 & 5478 & 705 & 11435 & 83 & 48 \\
\hline & $1.0362 \mathrm{~m} / \mathrm{s}$ & 14891 & 5263 & 1300 & 11528 & 97 & 75 \\
\hline & $1.3862 \mathrm{~m} / \mathrm{s}$ & 15963 & 4740 & 1520 & 9453 & 126 & 140 \\
\hline \multirow{4}{*}{$3600 \mathrm{~s}$} & $0.3454 \mathrm{~m} / \mathrm{s}$ & 18465 & 4059 & 1210 & 11056 & 36 & 18 \\
\hline & $0.6908 \mathrm{~m} / \mathrm{s}$ & 3693 & 3341 & 1240 & 11396 & 241 & 218 \\
\hline & $1.0362 \mathrm{~m} / \mathrm{s}$ & 10007 & 3696 & 1409 & 10965 & 101 & 132 \\
\hline & $1.3862 \mathrm{~m} / \mathrm{s}$ & 98878 & 2266 & 1545 & 10724 & 43 & 40 \\
\hline
\end{tabular}

\subsection{The Influence of Crystal Breakage on Nucleation Kinetics}

5.2.1. The Collision Rate. Figure 13 shows the relationship between collision rate and crystal breakage propensity. It can be demonstrated that the collision rate between crystals has a significant effect on the crystal breakage process. In
Figure 13, it is concluded that increasing the crystal collision rate increased the tendency of crystal breakage. With the increasing collision rate, the kinetic energy increases and hence is more likely to exceed the inherent strength of the crystal. Particle strength is the minimum amount of stress that may be applied to a particle to cause macroscopic 


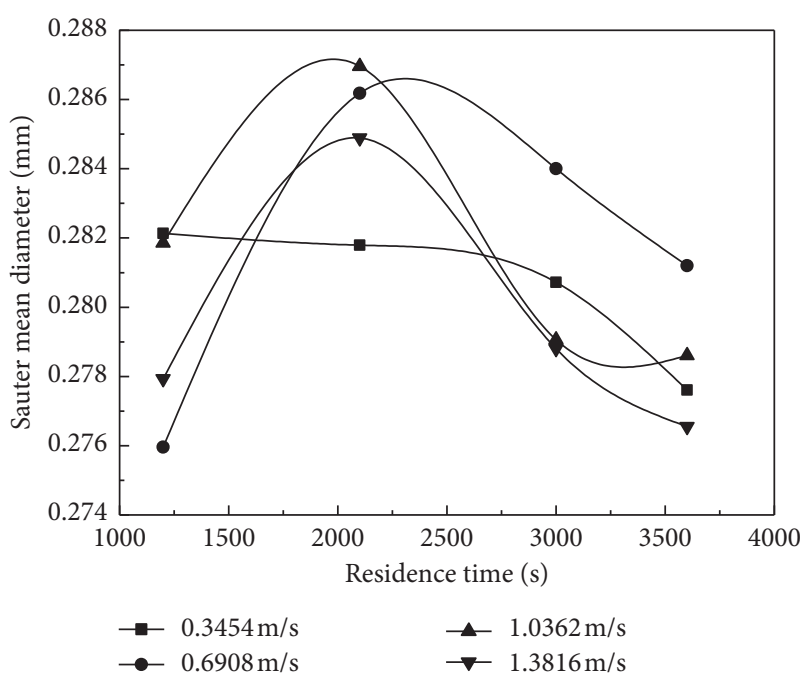

FIgURE 11: The influence of circulation flow rates on the Sauter mean size.

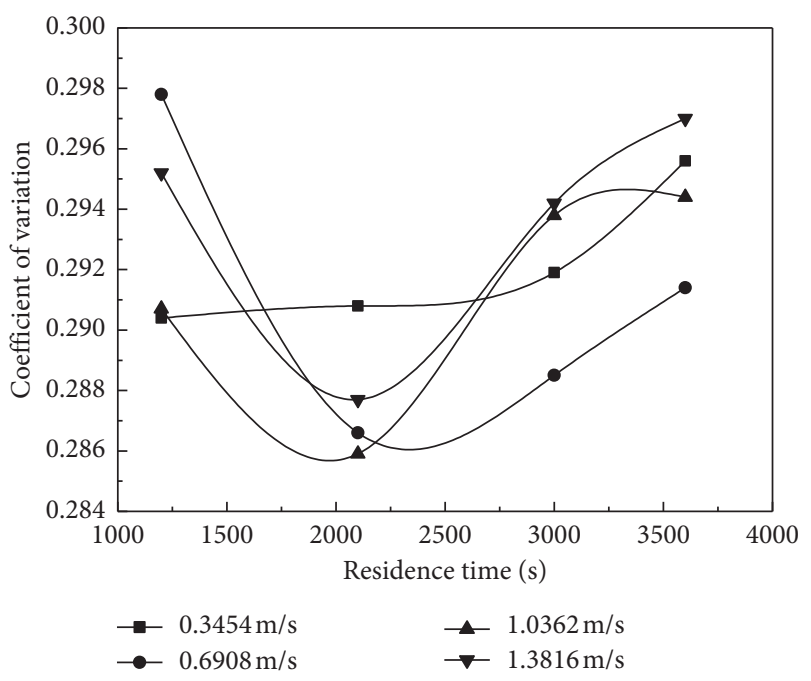

Figure 12: The influence of circulation flow rates on the coefficient of variation of crystal.

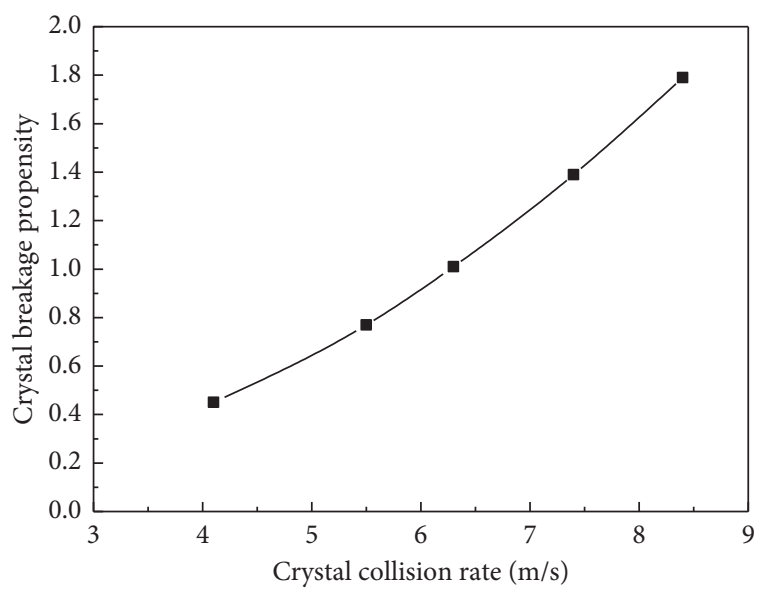

FIGURE 13: Relationship between collision rate and crystal breakage propensity. damage to the particle structure [16]. It has been generally found that crystals can break at certain impact energies through the propagation of meridional cracks, producing a number of large fragments. This response of the crystal is specific to the physical properties and morphology of the crystal. If other variables are constant, increasing collision rate has been shown to increase the magnitude of crystal attrition and breakage observed across a range of materials. The breakage caused by crystal collisions can lead to a large amount of fine debris, which not only triggers secondary nucleation but also ultimately affects product quality. In summary, it is widely accepted that, in order to minimize the degree of crystal breakage occurring within an FBC, a collision rate as close as is possible to the saltation rate should be used.

5.2.2. The Influence of Crystal Breakage on Nucleation Rate. Figure 14 shows the nucleation rate of crystal as a function of the breakage propensity. As can be seen, for a given supersaturation, the greater the tendency of breaking of crystal is, the higher the nucleation rate of crystal appearing is. The collision rate and properties of crystal have a significant influence on the breakage propensity. It is dependent on the incident kinetic energy. As mentioned earlier, the crystal breakage propensity is based on the assumption that, on each collision, the rate is sufficiently high to form lateral cracks on the crystal surface. The fracture surface of crystal is deformed due to the kinetic energy produced by collision. These surfaces have minimal fracture energy owing to the surfaces that have mainly cleavage planes. Therefore, the fraction of energy is small to generate a large amount of crack on the surface of crystals. Once a crack is formed, it propagates along a cleavage plane rapidly with a lower resistance and kinetic energy. Eventually, the formation of a large amount of debris leads to an increase in nucleation rate. These fractures cause the formation of large amounts of debris and trigger secondary nucleation leading to an increase in nucleation rate.

5.2.3. The Comparison of Nucleation Rate. As shown in Tables 3 and 4, the nonlinear regression fits provided by equation (6) and equation (27), demonstrating that the Botsaries model and coupled model describe the nucleation data well. The correspondence among experimental and two kinds of theoretical nucleation kinetics rate is shown in Figure 15. As shown previously, the Botsaries model suggests that the nucleation rate is proportional to the supersaturation, the suspension density, and the Reynolds number. These factors are all fluidized conditions rather than physical properties of the crystals. Hence, the Botsaries model has limitations in predicting the nucleation rate, making it necessary to obtain more precise experimental results in FBC for a more complete model. As can be seen, compared with the Botsaries model, the nucleation rate of sodium chloride predicted by the coupled model is demonstrated to correlate more closely to the experimental results, especially at high supersaturation in solution, deviating by less than $10 \%$. 


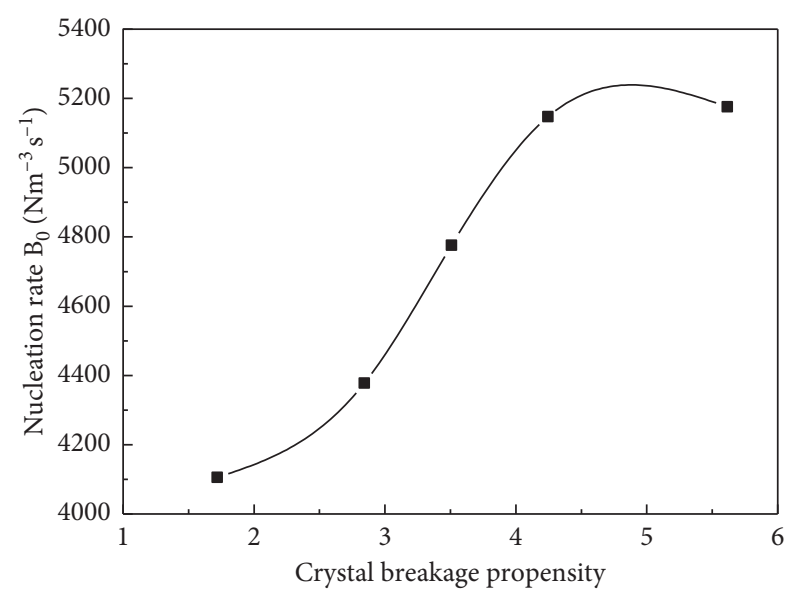

Figure 14: Relationship between crystal breakage propensity and nucleation rate.

TABLE 3: The parameters of the nucleation rate for Botsaries model.

\begin{tabular}{lcccccc}
\hline $\begin{array}{l}\text { Residence time } \\
\text { (s) }\end{array}$ & $K_{\mathrm{B}}$ & $i$ & $J$ & $k$ & $R^{2}$ \\
\hline $2100 \mathrm{~s}$ & $5.008 * 10^{3}$ & 0.07613 & 0.03333 & 0.0334 & 0.9965 \\
\hline
\end{tabular}

TABLE 4: The parameters of the nucleation rate for the coupled mode.

\begin{tabular}{lcccc}
\hline Residence time $(\mathrm{s})$ & $K_{\mathrm{B}}$ & $m$ & $n$ & $R^{2}$ \\
\hline $2100 \mathrm{~s}$ & $6.77091 * 10^{3}$ & 0.086426 & 0.011543 & 0.9987 \\
\hline
\end{tabular}

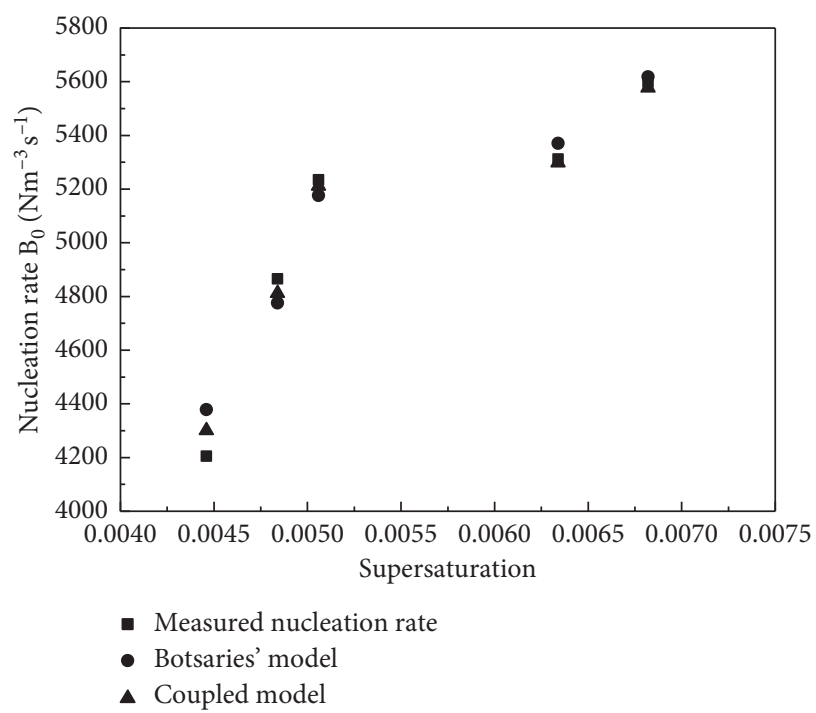

FIGURE 15: Comparison of the predicted and measured nucleation rate.

\section{Conclusion}

The aim of this article is to derive a new kinetic mathematical model of the contact nucleation of crystals that relates the number of crystal-crystal contact-collision sites to the crystal physical properties as represented by breakage propensity.
Hence, this study investigates the relationship between crystal contact nucleation and breakage process in FBC experiments. The effects of various operational parameters on crystal size distributions and breakage in an FBC are studied in detail. Our results indicate that the circulation flow rate and residence time are the main parameters that influenced breakage. The generation of fines caused by contact increased considerably as the circulation flow rate and residence time are increased. These debris will greatly increase the chance of secondary nucleation. From this perspective, we propose a nucleation kinetic model that takes into account the crystal breakage propensity. This nucleation kinetic model is based on the assumption that the work required for collision-contact sites have function with incident kinetic energy. It involves not only the technological condition of crystallization system but also the changes of crystal physical properties caused by the collision process. The results indicate that the coupled model gives a much more precise description of the crystal breakage process in contact nucleation.

\section{Data Availability}

All data generated or analyzed during this study are included in this published article. The data included in this study are available upon request from the corresponding author.

\section{Conflicts of Interest}

The authors declare that they have no conflicts of interest.

\section{Acknowledgments}

This work was supported by the Foundation for High-Level Talents in Higher Education of Sichuan University of Science \& Engineering (no. 2017RCL68), the Science and Technology Program of Sichuan, China (no. 2018CZ0025), the Foundation of Sichuan Educational Committee of China (no. 17ZA0280), and the Sichuan Province Universities and Colleges Key Laboratory Fund of Process Equipment and Control Engineering (no. GK201709).

\section{References}

[1] G. D. Botsaris, E. G. Denk, and J. Chua, "Nucleation in an impurity concentration gradient," AIChE Symposium Series, vol. 68, pp. 21-30, 1972.

[2] R. Y. Qian and G. D. Botsaris, "A new mechanism for nuclei formation in suspension crystallizers: the role of interparticle forces," Chemical Engineering Science, vol. 52, no. 20, pp. 3429-3440, 1997.

[3] Y. Asakuma, T. Tetahima, K. Maeda, M. Hideo, and D. Fukeu, "Attrition behavior by micro-hardness parameters in suspension-crystallization processes," Powder Technology, vol. 171, no. 2, pp. 75-80, 2007.

[4] D. Wu, Z. Gu, and Y. Li, "Attrition of catalyst particles in a laboratory-scale fluidized-bed reactor," Chemical Engineering Science, vol. 135, pp. 431-440, 2015.

[5] J. Garside and R. J. Davey, "Invited review secondary contact nucleation: kinetics, growth and scale-up," Chemical Engineering Communications, vol. 4, no. 4-5, pp. 393-424, 2007. 
[6] H. Emmerich, "Nucleation and growth kinetics in colloids and metals: a system- and scale-bridging approach to understanding the resulting morphology evolution," Philosophical Magazine Letters, vol. 87, no. 11, pp. 795-798, 2007.

[7] Y. Wang, J. Li, Y. Jin, J. Luo, M. Chen, and C. Yan, "Mixing efficiency of a rotor-stator spinning disc extractor," Chemical Engineering Journal, vol. 362, pp. 357-363, 2019.

[8] J. Garside and M. A. Larson, "Direct observation of secondary nuclei production," Journal of Crystal Growth, vol. 43, no. 6, pp. 694-704, 1978

[9] M. Ghadiri and Z. Zhang, "Impact attrition of particulate solids. Part 1: a theoretical model of chipping," Chemical Engineering Science, vol. 57, no. 17, pp. 3659-3669, 2002.

[10] Z. Zhang, Impact Attrition of Particulate Solids, University of Surrey, Guildford, England, 1994.

[11] R. Moreno-Atanasio and M. Ghadiri, "Mechanistic analysis and computer simulation of impact breakage of agglomerates: effect of surface energy," Chemical Engineering Science, vol. 61, no. 8, pp. 2476-2481, 2006

[12] S. Jin, M. Chen, Z. Li et al., "Design and mechanism of the formation of spherical $\mathrm{KCl}$ particles using cooling crystallization without additives," Powder Technology, vol. 329, pp. 455-462, 2018.

[13] C.-C. Su, L. D. Dulfo, M. L. P. Dalida, and M.-C. Lu, "Magnesium phosphate crystallization in a fluidized-bed reactor: effects of $\mathrm{pH}, \mathrm{Mg}: \mathrm{P}$ molar ratio and seed," Separation and Purification Technology, vol. 125, pp. 90-96, 2014.

[14] D. Shanthi, P. Selvarajan, and R. J. Mani, "Nucleation kinetics, growth and hardness parameters of l-alanine alaninium picrate (LAAP) single crystals," Optik, vol. 125, no. 11, pp. 2531-2537, 2014.

[15] F. Li, C. Briens, F. Berruti, and J. McMillan, "Particle attrition with supersonic nozzles in a fluidized bed at high temperature," Powder Technology, vol. 228, pp. 385-394, 2012.

[16] B. A. Kotzur, R. J. Berry, S. Zigan, P. García-Triñanes, and M. S. A. Bradley, "Particle attrition mechanisms, their characterisation, and application to horizontal lean phase pneumatic conveying systems: a review," Powder Technology, vol. 334, pp. 76-105, 2018. 

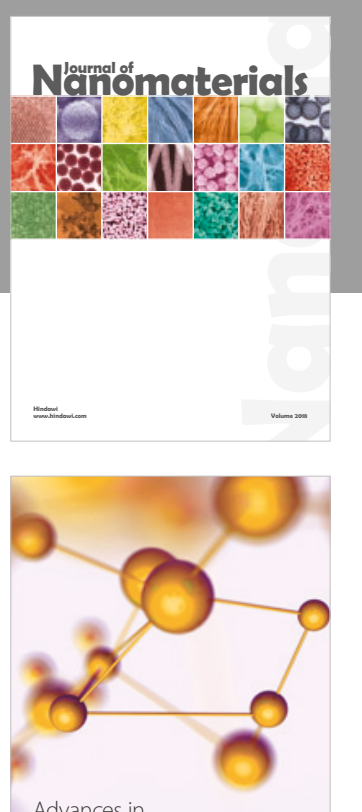

Physical Chemistry
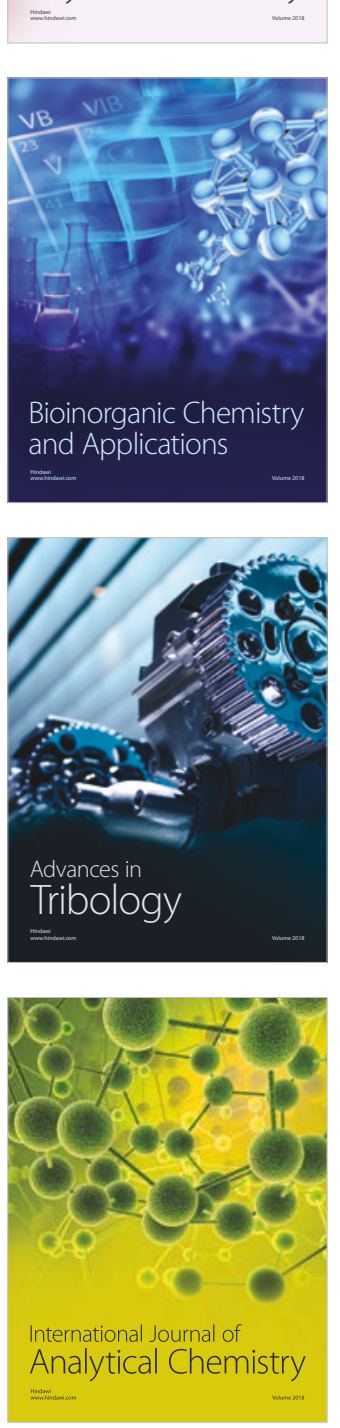

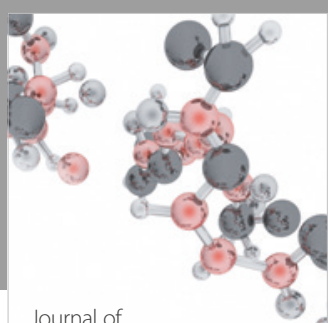

Analytical Methods

in Chemistry

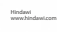

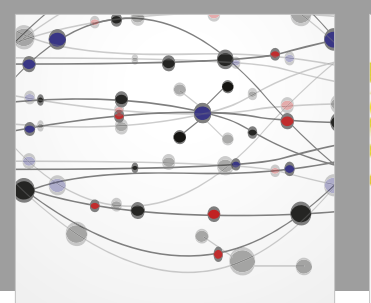

The Scientific World Journal

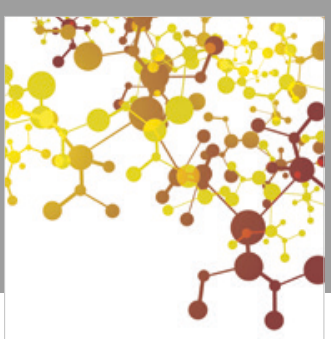

Journal of

Applied Chemistry
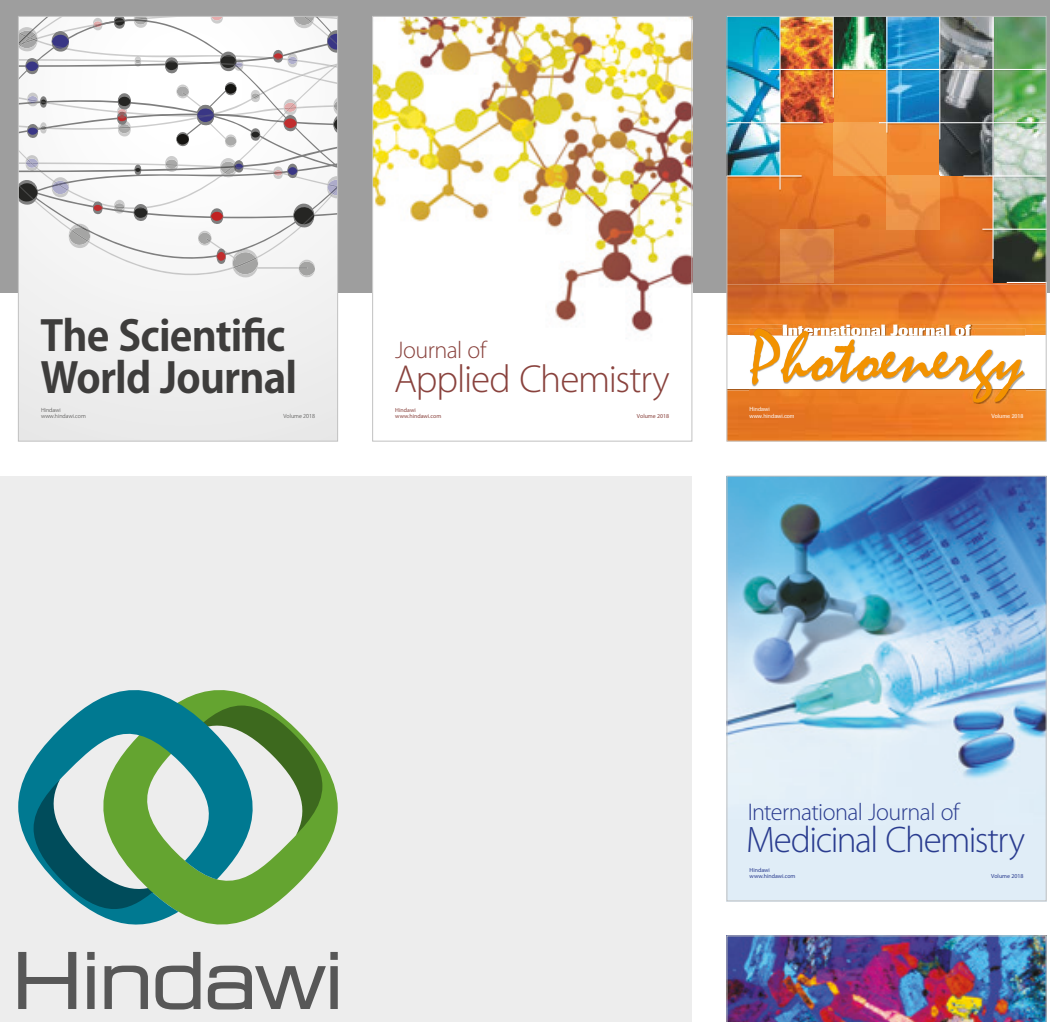

Submit your manuscripts at

www.hindawi.com
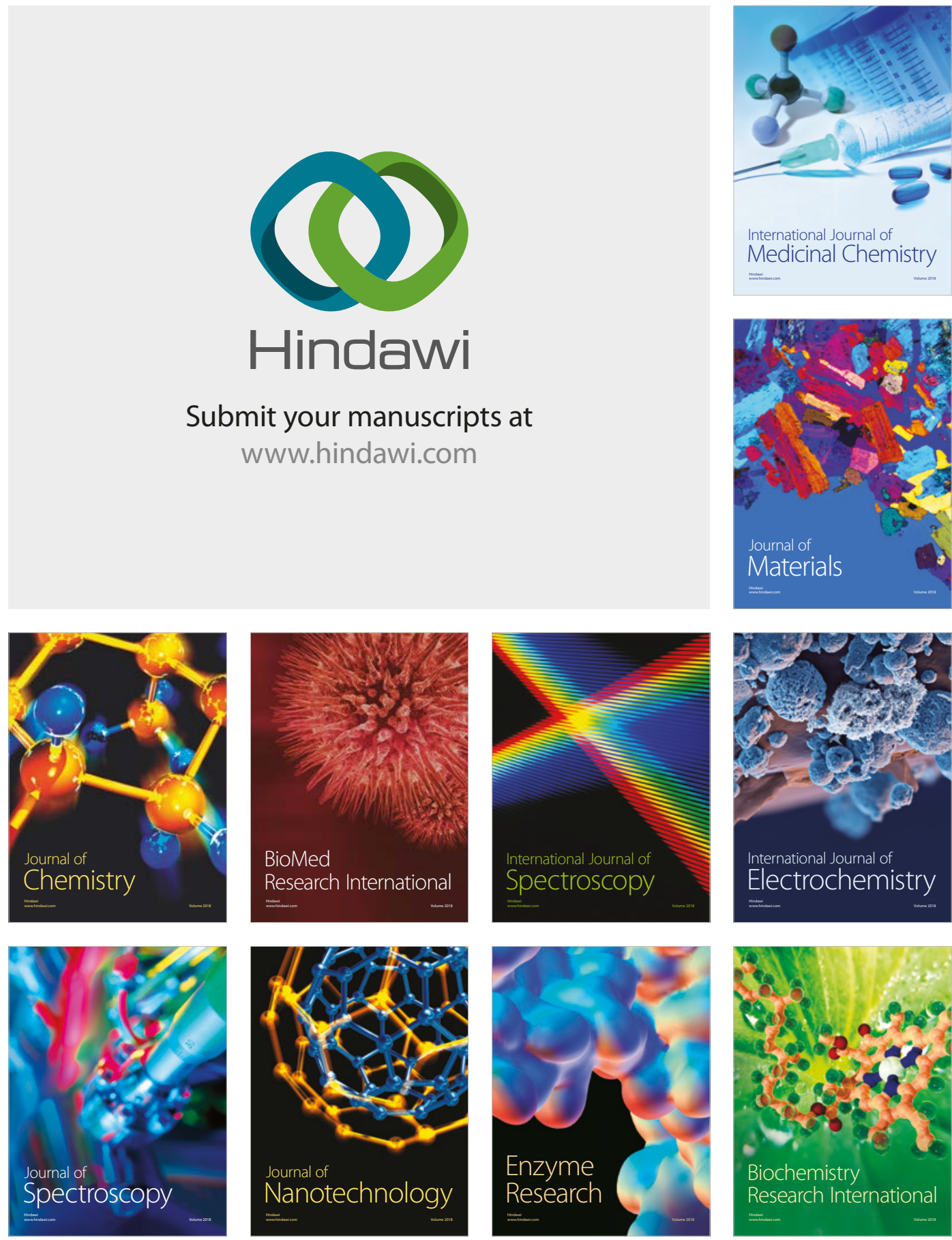
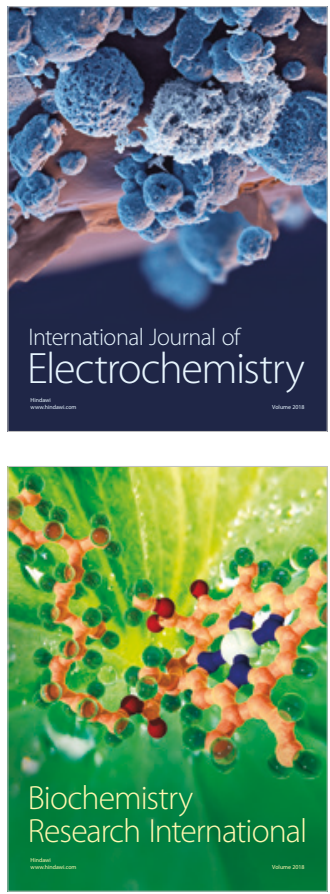